\title{
Influence of type 2 diabetes on symbolic analysis and complexity of heart rate variability in men
}

Sílvia CG Moura-Tonello ${ }^{1+}$, Anielle CM Takahashi ${ }^{1+}$, Cristina O Francisco ${ }^{1 \dagger}$, Sérgio LB Lopes ${ }^{2+}$, Adriano M Del Vale ${ }^{1+}$, Audrey Borghi-Silva ${ }^{1+}$, Angela MO Leal ${ }^{2+}$, Nicola Montano ${ }^{3+}$, Alberto Porta $^{4+}$ and Aparecida M Catai ${ }^{1 *+}$

\begin{abstract}
Background: Individuals with diabetes may develop cardiac autonomic dysfunction that may be evaluated by heart rate variability (HRV). The aim was evaluated heart rate variability (HRV) of individuals with type 2 diabetes, without cardiovascular autonomic neuropathy (CAN), in response to active postural maneuver by means of nonlinear analysis (symbolic analysis, Shannon and conditional entropy) and correlate HRV parameters between them, glycated hemoglobin and diabetes duration.
\end{abstract}

Methods: Nineteen men with type 2 diabetes without CAN (T2D) and nineteen healthy men (CG), age-range from 40 to 60 years were studied. We assessed HRV in supine and orthostatic position using symbolic analysis (0V\%, 1V\%, 2LV\% and 2UV\%), Shannon and conditional entropy (SE and NCI).

Results: In supine position T2D presented higher sympathetic modulation (OV\%) than CG. However, there was not any difference between groups for indexes of complexity (SE and $\mathrm{NCl}$ ). Furthermore, T2D presented a preserved response of cardiac autonomic modulation after active postural maneuver.

Conclusions: The present study showed that individuals with type 2 diabetes without CAN presented higher cardiac sympathetic modulation. However, the complexity of HRV was not influenced by imbalance of the autonomic modulation in individuals with type 2 diabetes. In addition, the response of autonomic nervous system in the heart remains preserved after active postural maneuver in individuals with type 2 diabetes, possibly due to the lack of CAN in this group.

Keywords: Heart rate variability, Type 2 diabetes mellitus, Symbolic analysis, Shannon entropy and conditional entropy

\section{Background}

Type 2 diabetes is a metabolic disorder of multiple etiologies characterized by hyperglycemia, insulin resistance and a variable degree of insulin secretory deficiency $[1,2]$. It is considered as a cardiovascular risk factor, as individuals with diabetes have double the risk of developing acute myocardial infarction and stroke than those who do not have it [3].

Individuals with diabetes may develop autonomic dysfunction related to the cardiovascular system, known as cardiovascular autonomic neuropathy (CAN). This dysfunction occurs where there are lesions in the peripheral autonomic fibers [4].

\footnotetext{
* Correspondence: mcatai@ufscar.br

${ }^{\dagger}$ Equal contributors

'Physiotherapy Department, Cardiovascular Physiotherapy Laboratory, Nucleus of Research in Physical Exercise, Federal University of São Carlos, São Paulo, Brazil Full list of author information is available at the end of the article
}

Cardiac autonomic dysfunction, characterized by alterations in the modulation the cardiac vagal, or sympathetic efferents, or in both, may be evaluated by heart rate variability (HRV) [5], which is a simple, non invasive measurement $[6,7]$ and is considered a predictor of cardiovascular morbidity and mortality [8]. It can be evaluated under conditions of rest $[9,10]$, and during provocative tests such as physical exercise $[11,12]$, the tilt test $[13,14]$ and active postural maneuver $[15,16]$.

Postural change promotes stimulus of the autonomic nervous system (ANS) in the heart by inducing an increase in sympathetic modulation during the tilt test $[14,17]$ and with active postural maneuver $[16,18]$. In addition, active postural maneuver is a simpler evaluation when compared with the tilt test, and it is, also, a low cost method that can be performed at the bedside $[16,18]$.

\section{Biomed Central}

(c) 2014 Moura-Tonello et al.; licensee BioMed Central Ltd. This is an Open Access article distributed under the terms of the Creative Commons Attribution License (http://creativecommons.org/licenses/by/2.0), which permits unrestricted use, distribution, and reproduction in any medium, provided the original work is properly credited. The Creative Commons Public Domain Dedication waiver (http://creativecommons.org/publicdomain/zero/1.0/) applies to the data made available in this article, unless otherwise stated. 
The HRV may be evaluated by linear and nonlinear methods. Javorka et al. [9] developed study involving nonlinear analysis to assess the complexity of HRV (Shannon and conditional entropy) of young patients with type 1 diabetes. They observed reduction in the complexity of HRV for this population. In addition, Javorka et al. [9] performed symbolic analysis and observed reduction index 2LV\% (index that reflects parasympathetic and sympathetic modulation with parasympathetic predominance). The authors attributed these results to vagal dysfunction [9]. However, there is a scarcity of studies that evaluate the HRV by nonlinear analysis in patients with type 2 diabetes.

Therefore, the primary objective was to evaluate the HRV of individuals with type 2 diabetes, without cardiovascular autonomic neuropathy (CAN), in response to active postural maneuver from the supine to orthostatic position, by means of nonlinear analysis (symbolic analysis, Shannon and conditional entropy). Our secondary aim was to correlate the duration of diabetes and glycated hemoglobin (HbA1c) with used HRV indexes.

\section{Methods}

\section{Subjects}

Thirty eight male volunteers, age-range from 40 to 65 years were evaluated. They were divided into two groups: one of subjects with type 2 diabetes in accordance with the recommendations of the American Diabetes Association [19] (T2D; $n=19)$ and the other group of control subjects (Control Group - CG; $\mathrm{n}=19$ ).

Volunteers were selected in accordance with the following criteria: sedentary, with aerobic functional classified as: very weak, weak, or reasonable according to the American Heart Association [20], non-smokers, non-drinkers and people without any kind of lung disease or systemic inflammatory disease. The exclusion criteria were as follows: diagnostic CAN (verified by clinical evaluation by an endocrinologist, slow deep breathing autonomic testing according to O'Brien et al. [21]; tachycardia at rest - heart rate $>100 \mathrm{bpm}$; orthostatic hypotension in reaction to active postural change - systolic blood pressure $>30 \mathrm{mmHg}$ ) [21], myocardial ischemia and/or cardiovascular pathologies on clinical examinations and clinical ergometric test conducted by a Physician, disease that incapacity the subject to remain in the orthostatic position actively, or walk and/or pedal the bicycle, and a body mass index (BMI) greater than $29.99 \mathrm{Kg} / \mathrm{m}^{2}$ for the CG.

The present study was approved by the Ethics Committee on Research in Human Beings of the Federal University of São Carlos (Protocol N. 093/2011). All the subjects who participated in the study were informed about the experimental procedures and signed a Formal Consent Agreement.

\section{Experimental procedure}

The experimental procedures were performed in the Cardiovascular Physiotherapy Laboratory at the Federal University of São Carlos and only blood collection was performed at the Clinical Analysis Laboratory. The study was always conducted in the morning period, considering the effects of the circadian rhythm. The experiments were carried out in a climate-controlled room $\left(22-23^{\circ} \mathrm{C}\right)$ with a relative air humidity of 50-60\%.

The protocols were performed in two days with a difference of one week between them: 1) blood collection, body composition evaluation, autonomic testing and cardiopulmonary exercise testing; 2) instantaneous R-R intervals (RRi) were recorded for HRV analysis. The volunteers were instructed not to practice moderate or heavy exercise, and not ingest food and/or stimulating or alcoholic beverages within 24 hours before the evaluations, and to fast for 12 hours on the day of blood collection.

\section{Laboratory exams}

The volunteers were subjected to venous blood collection for lipid profile, C-reactive protein (CRP), glycated hemoglobin (HbA1c) analysis, and afterwards the mean estimated glycemia was calculated. For these analyses ADVIA 1800 Chemistry System (Siemens, Tarrytown, NY, USA) was used.

\section{Body composition}

The body composition monitor Tanita Ironman (Tanita Corporation of America Inc, Illinois, USA) was used to evaluate the total body fat percentage of the volunteers.

\section{Cardiopulmonary exercise testing}

The symptom-limited cardiopulmonary exercise testing [22], was performed to confirm that subjects were classified at the same functional class [20]. The maximum volume of $\mathrm{O}_{2}$ consumption $\left(\mathrm{VO}_{2}\right.$ peak) was determined during an incremental cycle ergometer exercise, with increments calculated by the Wasserman formula [23], using a metabolic analyzer (CPX/D, MedGraphics, St. Paul, MN, USA).

\section{Heart rate variability (HRV)}

The HRV was obtained by the cardiofrequencymeter Polar $^{\oplus} \mathrm{RS} 800 \mathrm{CX}^{\mathrm{im}}$ (Polar Electro Oy, Kempele, Finland). This system captures the $\mathrm{R}$ wave of the ECG, with a sampling frequency of $500 \mathrm{~Hz}$, thus calculating the HR instantly and storing the RRi in the same way it is done with the Polar ${ }^{\circledR}$ S810i cardiofrequencymeter described by Vanderlei et al. [24].

The volunteers were instructed to lie down in the supine position, not to move and/or talk during RRi capture. Before starting the volunteers remained at rest in the supine position for $10 \mathrm{~min}$, in order to stabilize the cardiovascular variables. The RRi records the protocol 
consisted of $10 \mathrm{~min}$, with the volunteer lying on a stretcher. Then the systemic blood pressure was measured. Next, the volunteer was instructed to perform active postural change to the orthostatic position, and the system blood pressure was measured again. Finally, the RRi was recorded for the last time in the orthostatic position for the next 10 minutes.

The series length $\mathrm{N}$ was fixed at 256 beats in each position. The sequence of RRi with the greatest stability in the central region of the tachogram was selected for each volunteer in both positions. The same sequence selected was used to perform all the analyses.

\section{Symbolic dynamics} Shannon entropy

The Shannon Entropy is obtained by quantizing of the $\mathrm{RRi}$ series into six levels ranging from 0 to 5 , that means that each heartbeat corresponds to a symbol according to the level of the heartbeat. Therefore, they are organized into patterns with 3 symbols. The shape and distribution of these patterns was calculated with Shannon entropy (SE). The SE is large if its distribution is flat (all patterns are identically distributed and the series carries the maximum amount of information). However, if there is a subset of more probable patterns, while others are missing or infrequent (e.g., in a Gaussian distribution), SE will be small [25].

\section{Symbolic analysis}

Symbolic analysis was carried out by grouping the patterns with 3 symbols into four families as follows: (a) no variation (0V: all the symbols are equal, i.e. 2,2,2 or $4,4,4)$; (b) one variation (1V: 2 consecutive symbols are equal and the remaining symbol is different, i.e. 4,2,2 or $4,4,3$ ); (c) two like variations (2LV: the 3 symbols form an ascending or descending ramp, i.e. $5,4,2$ or $1,3,4)$; and (d) two unlike variations (2UV: the three symbols form a peak or a valley, i.e. $4,1,2$ or $3,5,3)$. The rate of occurrence for each pattern is defined as $0 \mathrm{~V} \%, 1 \mathrm{~V} \%, 2 \mathrm{LV} \%$, and $2 U V \%$ [26]. It has been observed that $0 \mathrm{~V} \%$ reflects only sympathetic modulation, $1 \mathrm{~V} \%$ reflects sympathetic and parasympathetic modulation, 2LV\% reflects sympathetic and parasympathetic modulation with vagal predominance and $2 \mathrm{UV} \%$ reflects, exclusively, vagal modulation $[14,26]$.

\section{Conditional entropy}

According to Porta et al. [26], conditional entropy (CE) measures the amount of information carried by the most recent sample of patterns that cannot be derived from a sequence of values of length of past patterns. $\mathrm{CE}$ is assessed with the complexity index (CI). We normalized this index with the Shannon entropy of the RRi to obtain a normalized complexity index (NCI) that expresses complexity in terms of dimensionless units. This index ranges from 0 (null information) to 1 (maximum information). The larger both indexes are, the greater the complexity, the lower the regularity.

\section{Statistical analysis}

The Shapiro-Wilk normality test was used to identify the distribution of data. Non-normal distribution data were transformed by the $\log 10$ and they became normal. Afterwards two-way ANOVA was used to analyze variables considering the effect of the group, effect of position and interaction among them. The Holm-Sidak post hoc was used to show the differences. The correlation between duration of diabetes and glycated hemoglobin (HbA1c) with HRV indexes were determined by Pearson. P value $<0.05$ was considered statistically significant. The data were presented as mean \pm SD. Sigma Plot software for Windows version 11.00 was used for data analysis.

\section{Results}

The data shown in Table 1 were presented to characterize the studied sample. There was significant difference between the groups for HbA1c and estimated mean glycemia, an expected result, since these exams are generally shown to be altered in individuals with diabetes (Table 1) [27].

T2D group was evaluated by an endocrinologist and was subjected to tests that assess autonomic nervous system (slow deep breathing autonomic testing, tachycardia at rest and orthostatic hypotension in reaction to active postural). All subjects had normal values for autonomic testing and in clinical evaluation all subjects denied dizziness or sweating with postural maneuver, and they did not report sexual dysfunction, sensory loss of vibration, pressure, pain and temperature perception in the lower limbs, therefore all subjects were diagnosed without CAN.

T2D medication to control diabetes (hypoglycemic drugs and/or insulin). In addition, some individuals with diabetes used too antihypertensive, hypolipidemic drugs (Table 1).

Both groups showed an increase in HR and reduction in mean RRi in active postural maneuver. To variance of RRi the groups were different regardless of posture, with T2D presenting lower values than CG in both positions (Table 2).

With respect to Shannon entropy, there were not group and position effect. Whereas the normalized complexity index $(\mathrm{NCI})$ presented position effect $(\mathrm{p}<0.05)$, because both groups presented a reduction in their values in the transition from the supine to orthostatic position (Figure 1).

Regarding the symbolic analysis indexes, there was an effect of both groups and position on $0 \mathrm{~V} \%, 1 \mathrm{~V} \%$ and $2 \mathrm{LV} \%$. The active postural maneuver led to an increase on $0 \mathrm{~V} \%$ and a decrease on $1 \mathrm{~V} \%$ and $2 \mathrm{LV} \%$ for both groups. In addition, T2D presented higher values for $0 \mathrm{~V} \%$ and 
Table 1 Characteristics of evaluated groups

\begin{tabular}{|c|c|c|c|}
\hline Characteristics & T2D & CG & $P$-value \\
\hline Age (years) & $50.53 \pm 6.96$ & $50.26 \pm 7.96$ & 0.345 \\
\hline Body mass (Kg) & $86.64 \pm 13.86$ & $80.24 \pm 9.38$ & 0.057 \\
\hline Height (m) & $1.74 \pm 0.09$ & $1.75 \pm 0.08$ & 0.823 \\
\hline BMI $\left(\mathrm{Kg} / \mathrm{m}^{2}\right)$ & $28.26 \pm 4.13$ & $26.21 \pm 1.77$ & 0.062 \\
\hline Percentage of total body fat & $24.94 \pm 6.20$ & $23.38 \pm 3.61$ & 0.384 \\
\hline VO2 peak (ml/min) & $1672.05 \pm 345.01$ & $1850.89 \pm 238.09$ & 0.070 \\
\hline Time of diabetes (years) & $11.13 \pm 6.41$ & - & - \\
\hline \multicolumn{4}{|l|}{ Laboratory Exams } \\
\hline PCR (mg/dL) & $1.12 \pm 1.48$ & $0.69 \pm 0.66$ & 0.874 \\
\hline HbA1c (\%) & $8.54 \pm 2.15$ & $5.85 \pm 0.30$ & $<0.001^{*}$ \\
\hline $\mathrm{HbA} 1 \mathrm{c}(\mathrm{mmol} / \mathrm{mol})$ & $69.80 \pm 23.55$ & $40.44 \pm 3.26$ & $<0.001^{*}$ \\
\hline Estimated mean glycemia (mg/dL) & $197.79 \pm 61.91$ & $119.47 \pm 9.95$ & $<0.001^{*}$ \\
\hline Total cholesterol (mg/dL) & $193.79 \pm 28.61$ & $198.21 \pm 39.33$ & 0.635 \\
\hline HDL-cholesterol (mg/dL) & $45.37 \pm 10.32$ & $46.79 \pm 11.02$ & 0.573 \\
\hline LDL-cholesterol (mg/dL) & $113.53 \pm 32.12$ & $119.26 \pm 30.62$ & 0.253 \\
\hline VLDL-cholesterol (mg/dL) & $33.84 \pm 18.49$ & $31.05 \pm 16.11$ & 0.452 \\
\hline Triglycerides (mg/dL) & $170.47 \pm 92.57$ & $156.37 \pm 80.06$ & 0.093 \\
\hline \multicolumn{4}{|l|}{ Risk factors } \\
\hline Hypertension & $2(10.53 \%)$ & - & - \\
\hline Obesity & $5(26.31 \%)$ & - & - \\
\hline Dyslipidemia & $7(36.84 \%)$ & $9(47.37 \%)$ & - \\
\hline \multicolumn{4}{|l|}{ Medications } \\
\hline Oral hypoglycemic drugs & $8(42.11 \%)$ & - & - \\
\hline Insulin & $4(21.05 \%)$ & - & - \\
\hline Oral hypoglycemic drugs + insulin & $4(21.05 \%)$ & & \\
\hline Anti-hypertensive drugs & $5(26.31 \%)$ & - & - \\
\hline ACE Inhibitor & $1(5.26 \%)$ & - & - \\
\hline - Calcium channel blocker (amlodipina) & $1(5.26 \%)$ & - & - \\
\hline - Angiotensin II receptor antagonist & $2(10.53 \%)$ & - & - \\
\hline - Hydrochlorothiazide & $1(5.26 \%)$ & - & - \\
\hline - Clonidine & $1(5.26 \%)$ & - & - \\
\hline - Hypolipidemic drug & $2(10.53 \%)$ & $3(15.79 \%)$ & \\
\hline \multicolumn{4}{|l|}{ Deep breathing testing } \\
\hline$E / I$ & $1.27 \pm 0.20$ & $1.29 \pm 0.16$ & 0.352 \\
\hline$\triangle \mathrm{IE}$ & $18.53 \pm 14.94$ & $16.73 \pm 8.82$ & 0.494 \\
\hline
\end{tabular}

The data are presented in mean \pm standard deviation. $\mathrm{T} 2 \mathrm{D}=$ group with type 2 diabetes; $\mathrm{CG}=\mathrm{Control} \mathrm{Group} ; \mathrm{BMI}=$ body mass index; $\mathrm{VO} \mathrm{O}_{2}$ peak $=$ oxygen consumption at peak of physical effort; $\mathrm{PCR}=\mathrm{C}$-reactive protein; HbA1c $=$ glycated hemoglobin. ${ }^{*} \mathrm{p}<0.05$.

lower for the index $1 \mathrm{~V} \%$ and $2 \mathrm{LV} \%$ in both positions when compared with CG. Whereas the index 2UV\% was affected only by position effect, which shows that regardless of the group, there is alteration of this index with active postural change (Figure 1).

Table 3 show that there was not a correlation [28] between parameters of HRV and HbA1c, duration of diabetes and indexes of slow deep breathing in T2D.

\section{Discussion}

The main finding of the present study is that individuals with type 2 diabetes without diagnosed of CAN presented higher sympathetic modulation than CG, but the imbalance of the autonomic modulation did not influence the complexity of HRV yet. In addition, the response of ANS in the heart remains preserved after active postural maneuver in individuals with type 2 diabetes without CAN. 
Table 2 Systolic and diastolic blood pressure $(\mathrm{mmHg})$, heart rate (bpm), R-R interval (RRi) and heart rate variance (VAR)

\begin{tabular}{|c|c|c|c|c|c|c|c|c|c|c|c|}
\hline \multirow[t]{3}{*}{ Variables } & \multicolumn{4}{|c|}{$\mathrm{T} 2 \mathrm{D}$} & \multicolumn{4}{|c|}{ CG } & \multicolumn{3}{|c|}{$P$-value } \\
\hline & \multicolumn{2}{|c|}{ Supine } & \multicolumn{2}{|c|}{ Orthostatic } & \multicolumn{2}{|c|}{ Supine } & \multicolumn{2}{|c|}{ Orthostatic } & \multirow[t]{2}{*}{ Group } & \multirow[t]{2}{*}{ Position } & \multirow[t]{2}{*}{ Interaction } \\
\hline & Mean \pm SD & $\mathrm{Cl}$ & Mean \pm SD & $\mathrm{Cl}$ & Mean \pm SD & $\mathrm{Cl}$ & Mean \pm SD & $\mathrm{Cl}$ & & & \\
\hline SBP $(\mathrm{mmHg})$ & $135 \pm 16.4$ & $(126.2-143.8)$ & $128.8 \pm 16.0$ & $(120.2-137.3)$ & $129.0 \pm 9$ & (124.3-133.9) & $122.2 \pm 11.00$ & (116.4-128.0) & 0.068 & 0.056 & 0.926 \\
\hline $\mathrm{DBP}(\mathrm{mmHg})$ & $86.3 \pm 12.0$ & $(79.8-92.7)$ & $82.8 \pm 11.0$ & $(77-88.7)$ & $82.2 \pm 8$ & (78-86.4) & $76.4 \pm 20.3$ & $(65.6-87.3)$ & 0.131 & 0.182 & 0.735 \\
\hline HR (bpm) & $72.8 \pm 8.7$ & $(68.6-77.0)$ & $83.3 \pm 11.5$ & (77.7-88.8) & $67.3 \pm 10.4$ & $(62.3-72.3)$ & $81.1 \pm 13.5$ & $(74.6-87.6)$ & 0.140 & $<0.001^{*}$ & 0.517 \\
\hline RRi mean (ms) & $836.4 \pm 106.1$ & (785.3-887.6) & $734.4 \pm 107.5$ & $(682.5-786.2)$ & $911.3 \pm 135.3$ & (846.1-976.6) & $760.1 \pm 131.7$ & (696.7-823.6) & 0.074 & $<0.001^{*}$ & 0.378 \\
\hline $\operatorname{VAR}\left(\mathrm{ms}^{2}\right)$ & $485.4 \pm 304.3$ & $(338.8-632.1)$ & $327.0 \pm 197.1$ & (232.0-422.0) & $1010.6 \pm 745$ & $(651.6-1369.7)$ & $763.9 \pm 623.6$ & $(463.3-1064.4)$ & $<0.001^{*}$ & 0.187 & 0.885 \\
\hline
\end{tabular}

The data are presented in mean \pm standard deviation (Mean $\pm \mathrm{SD}$ ) and confidence intervals of mean (Cl). T2D = group type 2 diabetes; $\mathrm{CG}=$ Control Group; $\mathrm{SBP}=$ systolic blood pressure; $\mathrm{DBP}=$ diastolic blood pressure; $H R=$ heart rate; $i R R=R-R$ interval between $R$ waves; $V A R=$ variance of $R R i ;{ }^{*} p<0.05$. 

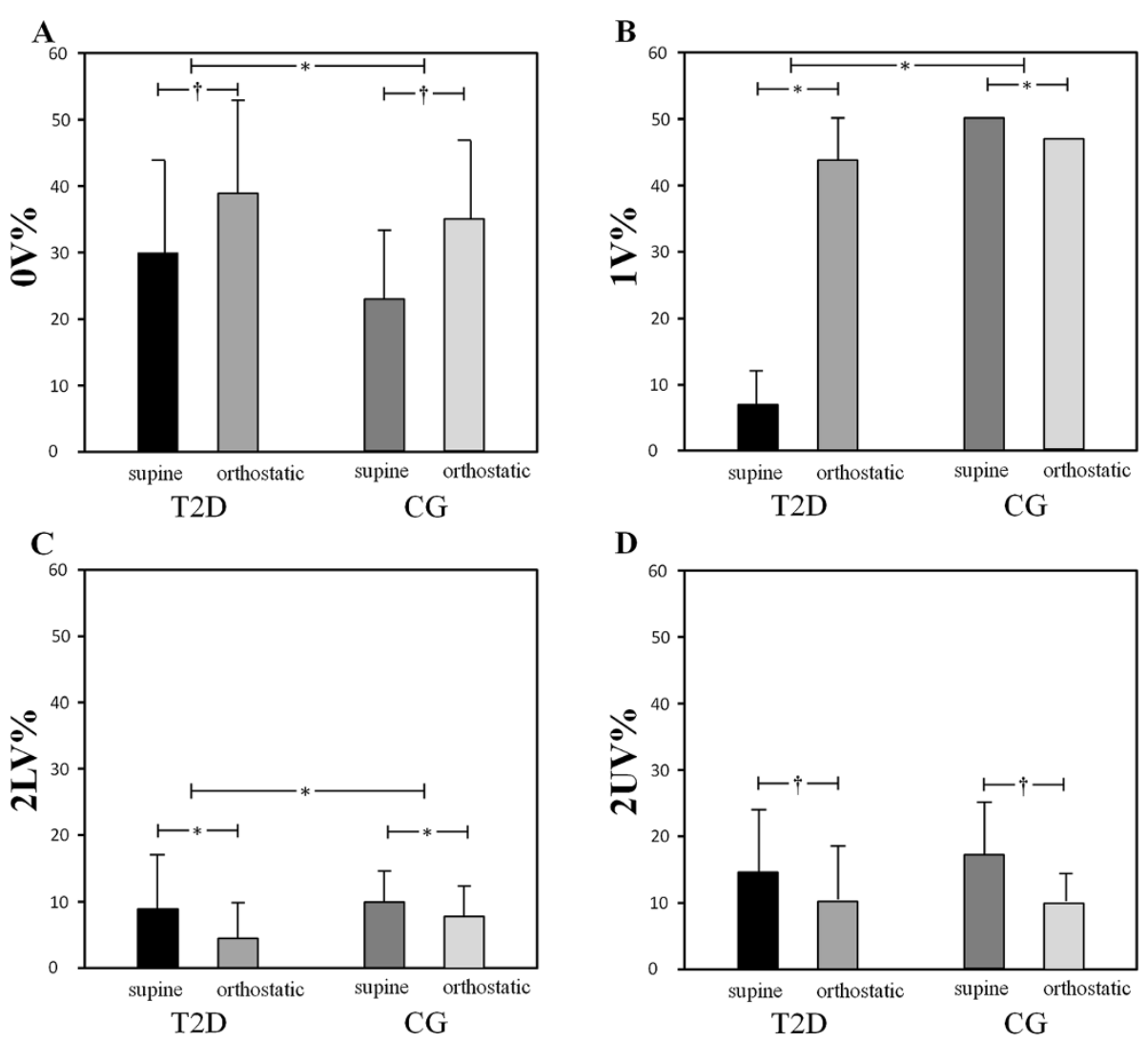

D
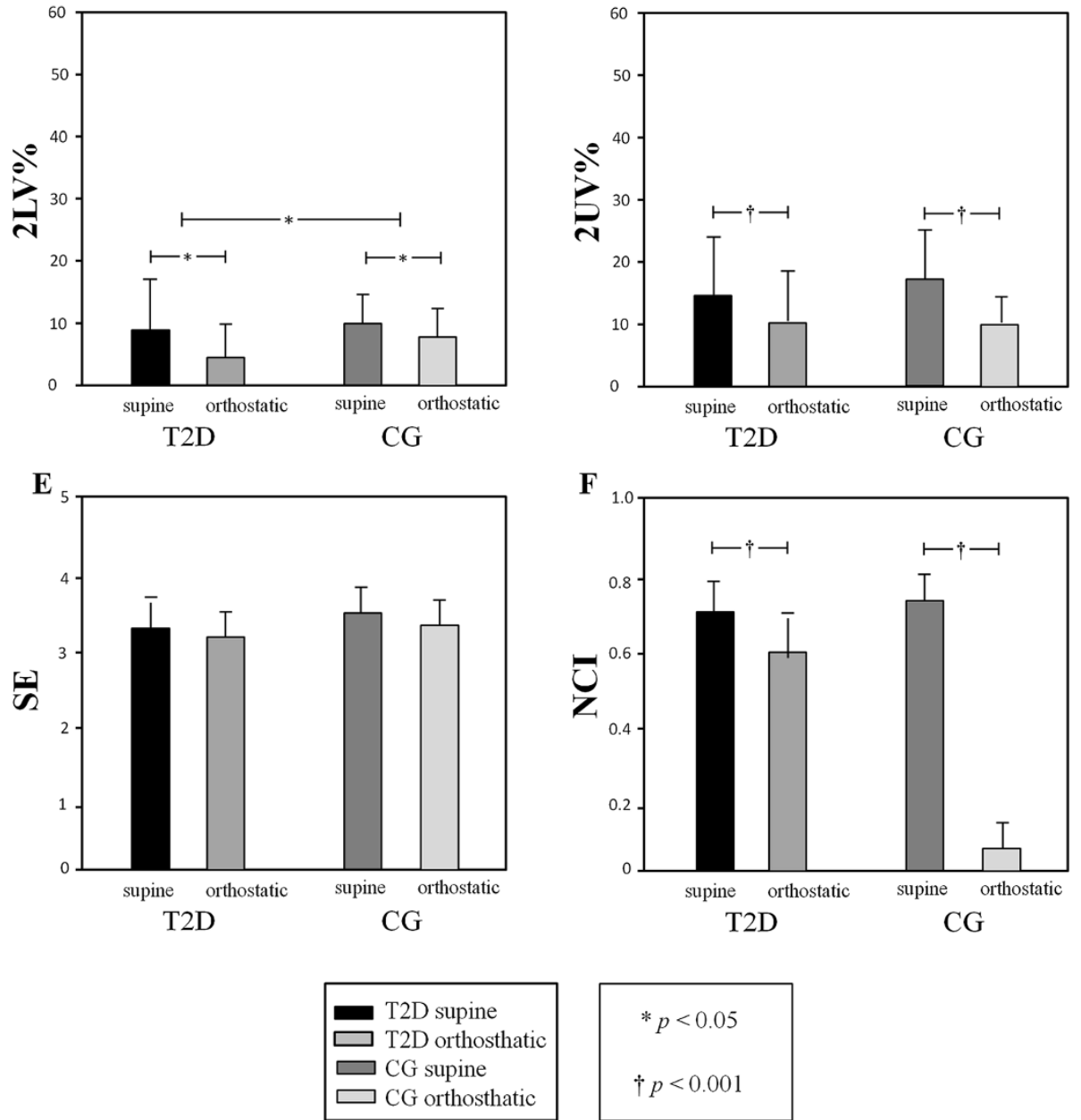

Figure 1 Symbolic dynamics of HRV for individuals with type 2 diabetes (T2D) and and control group (CG). The symbol *indicates $p<0.05$ and t indicates $p<0.001$. A: OV\% index; B: 1V\% index; C: 2LV\% index; D: 2UV\% index; E: SE = Shannon entropy; F: NCl = normalized complexity index.

\section{Effect of diabetes}

In the present study we observed that $\mathrm{T} 2 \mathrm{D}$ presented an increase of sympathetic modulation, characterized by an increase of index $0 \mathrm{~V} \%$ regardless of the position adopted. In addition, T2D presented decrease of $2 \mathrm{LV} \%$ that reflects sympathetic and parasympathetic modulation, with parasympathetic predominance. There was not difference between groups for $2 \mathrm{UV} \%$ that reflects exclusively vagal modulation. Javorka et al. [9] also found a reduction in $2 \mathrm{LV}$ $\%$ with statistically significant difference when compared youngsters with type 1 diabetes with the control group in the supine position. 
Table 3 Correlation between the parameters of heart rate variability and glycated hemoglobin, duration of diabetes and indexes of slow deep breathing in T2D

\begin{tabular}{|c|c|c|c|c|c|c|}
\hline & OV\% & $1 \mathrm{~V} \%$ & 2LV\% & $2 U V \%$ & SE & $\mathrm{NCl}$ \\
\hline \multicolumn{7}{|l|}{ Supine } \\
\hline \multirow[t]{2}{*}{$\mathrm{HbA1c}(\%)$} & $r=-0.03$ & $r=-0.07$ & $r=-0.10$ & $r=0.20$ & $r=0.01$ & $r=-0.03$ \\
\hline & $p=0.91$ & $p=-0.78$ & $p=0.67$ & $p=0.40$ & $p=0.94$ & $p=0.88$ \\
\hline \multirow[t]{2}{*}{ Duration of Diabetes } & $r=0.02$ & $r=0.17$ & $r=0.30$ & $r=-0.25$ & $r=0.12$ & $r=-0.19$ \\
\hline & $p=0.93$ & $p=0.50$ & $p=0.22$ & $p=0.29$ & $p=0.63$ & $p=0.43$ \\
\hline \multirow[t]{2}{*}{$E / I$} & $r=-0.24$ & $r=0.35$ & $r=0.13$ & $r=0.18$ & $r=0.16$ & $r=0.31$ \\
\hline & $p=0.35$ & $p=0.18$ & $p=0.63$ & $p=0.50$ & $p=0.55$ & $p=0.23$ \\
\hline \multirow[t]{2}{*}{$\triangle \mathrm{IE}$} & $r=0.08$ & $r=0.256$ & $r=-0.19$ & $r=-0.03$ & $r=-0.24$ & $r=0.21$ \\
\hline & $p=0.78$ & $p=0.34$ & $p=0.50$ & $p=0.93$ & $p=0.37$ & $p=0.44$ \\
\hline \multicolumn{7}{|l|}{ Orthostatic } \\
\hline \multirow[t]{2}{*}{$\mathrm{HbA1c}(\%)$} & $r=-0.13$ & $r=-0.06$ & $r=-0.08$ & $r=-0.08$ & $r=-0.01$ & $r=0.02$ \\
\hline & $p=0.50$ & $p=0.60$ & $p=0.80$ & $p=0.71$ & $p=0.94$ & $p=0.91$ \\
\hline \multirow[t]{2}{*}{ Duration of Diabetes } & $r=0.17$ & $r=-0.01$ & $r=-0.19$ & $r=-0.07$ & $r=-0.10$ & $r=-0.35$ \\
\hline & $p=0.50$ & $p=0.96$ & $p=0.42$ & $p=0.76$ & $p=0.67$ & $p=0.14$ \\
\hline \multirow[t]{2}{*}{$E / I$} & $r=-0.16$ & $r=0.22$ & $r=-0.10$ & $r=0.13$ & $r=0.01$ & $r=0.14$ \\
\hline & $p=0.56$ & $p=0.42$ & $p=0.71$ & $p=0.63$ & $p=0.97$ & $p=0.61$ \\
\hline \multirow[t]{2}{*}{$\triangle \mathrm{IE}$} & $r=0.23$ & $r=-0.274$ & $r=-0.33$ & $r=0.14$ & $r=-0.34$ & $r=0.18$ \\
\hline & $p=0.39$ & $p=0.30$ & $p=0.22$ & $p=0.62$ & $p=0.20$ & $p=0.52$ \\
\hline
\end{tabular}

$\mathrm{T} 2 \mathrm{D}=$ group type 2 diabetes; Symbolic analysis indexes (0V\%, 1V\%, 2LV\% and 2UV\%); SE = Shannon Entropy; $\mathrm{Cl}=\mathrm{complexity} \mathrm{Index;} \mathrm{NCl}=$ normalized complexity index; $\mathrm{E} / \mathrm{I}=$ relationship between expiration and inspiration; $\Delta \mathrm{IE}=$ heart rate during inspiration - heart rate during expiration. There were no significant correlations.

In addition, $\mathrm{T} 2 \mathrm{D}$ presented a lower $1 \mathrm{~V} \%$ value than $\mathrm{CG}$, in spite of its position. Probably, this result is due to the dysfunction of the ANS because this index reflects both sympathetic and parasympathetic modulation, with sympathetic predominance [25].

In the individuals with type 2 diabetes who develop CAN, the first to present lesion is the vagal nerve, and this allows a greater action of the sympathetic system on the heart [29]. However, our subjects did not present CAN, perhaps, they did not present irreversible lesion in vagal nerve yet, because there was not any difference between T2D and CG for $2 \mathrm{UV} \%$, but T2D presented a autonomic dysfunction reflected in a decrease of $2 \mathrm{LV} \%$ and an increase of $0 \mathrm{~V} \%$. Javorka et al. [30] suggested that the autonomic dysfunction in initial phases may be a consequence of functional changes of the neurons which can be reversible, for example mentioned by the authors, endoneural edema caused by hyperglycemia.

In the study of Khandoker et al. [31], it was observed that patients with type 2 diabetes with CAN presented lower complexity evaluated by sample entropy in comparison with the group with type 2 diabetes without neuropathy. Javorka et al. [30] did not find difference between healthy subjects and subjects with type 1 diabetes for complexity of HRV using also sample entropy. In another study, using $\mathrm{NCI}$, the authors observed a reduction of complexity in subjects with type 1 diabetes compared with healthy subjects [9]. In our study, we did not find difference between subjects with type 2 diabetes and healthy subjects for complexity of HRV evaluated by Shannon entropy (SE) (that quantifies the degrees of complexity of the distribution of temporal sequence patterns of HRV that may be absent or not very frequent, determining lower complexity) and conditional entropy (NCI) (form in which these patterns are related, that is to say, the sequence in which they are organized). Nevertheless, it is interesting to note that in the present study, the complexity of HRV was not affected by the presence of diabetes, this is possibly due to the absence of cardiac autonomic neuropathy installed, even with known autonomic imbalance.

\section{Effect of postural change}

Active postural maneuver is an important method to evaluate the HRV because it stimulates the ANS, and moreover it is a simpler and cheaper than tilt test $[16,18]$. In the present study both groups presented an increased in the heart rate (HR) and a reduction in the mean of RRi with active postural maneuver. A similar result was observed by Perseguini et al. [16] with postural change in healthy men.

Indexes of symbolic analysis showed effect of postural maneuver in modulation of ANS in heart for both groups. There was increasing $0 \mathrm{~V} \%$ and reduced $1 \mathrm{~V} \%$, 2LV\% and 2UV\%. Similar results were found in other studies [14,25,32]. This response may be attributed to 
the reduction in venous return, and consequently, an elevation in $\mathrm{HR}$, due to cardiac autonomic regulation (inhibition of vagal and stimulation of sympathetic modulation), which is mediated by the adjustments of the cardiopulmonary and arterial baroreceptors with postural change from the supine to the orthostatic position [33]. These results showed that both groups responded to maneuver, i.e., the autonomic modulation of $\mathrm{T} 2 \mathrm{D}$ without CAN remains able to properly respond to active postural maneuver.

As regards Shannon entropy analysis, both groups did not present a reduction in complexity with postural change. These findings were not in agreement with those of the study of Porta et al. [25], who evaluated healthy subjects and observed a reduction in Shannon entropy during the tilt test, and attributed this response to the increase in the percentage of absent patterns. This difference may be due to postural change have been active and not through a postural table, ie the active postural maneuvers may have less influence in ANS compared to tilt test.

Conditional entropy is a measure of complexity of the dynamics between a pattern and the next one (regularity), so that the higher the regularity, the lower the value of conditional entropy index (NCI) [25]. Porta et al. [34], studying healthy young subjects, observed an increase in the regularity of the temporal sequence with the tilt test, and attributed this finding to the increase in sympathetic modulation and reduction in parasympathetic modulation, which were capable of reducing the complexity of the $\mathrm{RRi}$. In the present study NCI also presented reduction with active postural change in both groups, which shows a greater regularity in the temporal sequence with orthostatic change, due to sympathetic predominance (0V\%) and reduction in parasympathetic modulation (2UV\%) in response to the active postural maneuver. These results show that there is a reduction in complexity in the presence of an increase in sympathetic modulation and decrease in vagal modulation. This data is in accordance with Porta et al. [26]. Therefore, both groups had reduction in complexity (NCI) with active postural change. Thus, these groups presented a preserved response of cardiac autonomic modulation after active postural maneuver, i.e., diabetes did not influence the results of complexity evaluated with active postural maneuvers. We attributed this result to the absence of CAN, since the subjects with diabetes did not have neuropathy installed.

\section{Glycemic control and duration of diabetes}

The injury mechanisms of sympathetic and parasympathetic branches are not completely understood. Several hypotheses are considered in the process of pathogenesis of CAN. The hyperglycemia is considered the permissive pathogenetic factor [35] because it activates various biochemical pathway leading development and progression of CAN [5,36,37]. Therefore, due to this hypothesis, glycemic control is considered the main approach in the treatment of CAN [35]. Furthermore, the duration of the disease has been studied as a factor involved in cardiovascular autonomic neuropathy [38].

Previous studies with diabetes type 1 confirmed the correlation between HRV parameters and HbA1c and duration of diabetes $[39,40]$, but there are others studies that did not confirm these association [30,38]. Study with diabetes type 1 and 2 found no association between HRV and HbA1c [38]. While Nolan et al. [41] found a negative association of vagal modulation with the duration of type 2 diabetes in men. In the present study there was not any association between HRV and HbA1c and duration of type 2 diabetes.

\section{Clinical implications}

The use of the symbolic analysis in the periodic evaluation of subjects with type 2 diabetes may help in the

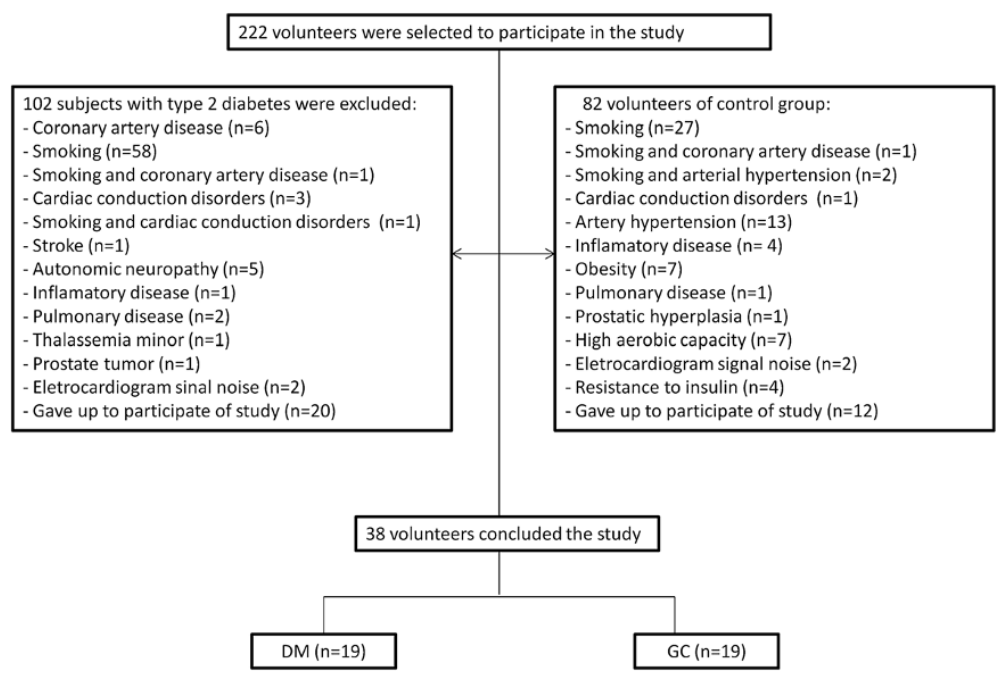

Figure 2 Flow diagram indicating sampling loss in the study. 
early diagnosis of cardiac autonomic imbalance and even CAN, which allows interventions and guidance to be provided, before greater complications become established [5].

Subjects with type 2 diabetes without cardiovascular autonomic neuropathy installed may have cardiac autonomic dysfunction. It can be observed by the fact that T2D began with increased value of the index related to the sympathetic autonomic system (0V\%) and decreased value of the $2 \mathrm{LV} \%$ that reflects sympathetic and parasympathetic with predominance vagal modulation. The evaluation of HRV before and after active postural maneuver is a simple and low cost test that can be performed at the bedside [16]. Furthermore, this test may be used in the clinical evaluation because it is a stimulus for ANS $[16,18]$. However, in present investigation, it was not possible to observe differences between groups with this test. This, possibly, occurred due to lack of neuropathy in TD2 and both groups present ANS response with active postural maneuvers.

\section{Study limitations}

The number of subjects studied in each group is small due to the sample loss during the study (Figure 2). However, it is noteworthy that the number of subjects was sufficient to detect some important differences in HRV as described above. Furthermore, we did not analyze the fasting glucose and insulin (laboratory tests that are common in the literature), however there are studies that did not show correlation between these laboratory tests and HRV [42,43].

\section{Conclusions}

The present study showed that individuals with type 2 diabetes without CAN presented higher sympathetic modulation. However, the complexity of HRV was not influenced by imbalance of the autonomic modulation in individuals with type 2 diabetes. In addition, the response of ANS in the heart remains preserved after active postural maneuver in individuals with type 2 diabetes, possibly due to lack of CAN in this group.

\footnotetext{
Abbreviations

ANS: Autonomic nervous system; BMI: Body mass index; CAN: Cardiovascular autonomic neuropathy; CG: Control group; CRP: C-reactive protein; $\triangle \mathrm{IE}$ : Difference between heart beat during inspiration and expiration; E/I: Ratio of the longest RR interval during expiration and the shortest RR interval during inspiration; HbA1c: Glycated hemoglobin; HR: Heart rate; HRV: Heart rate variability; NCl: Normalized complexity index; RRi: Interval between successive R waves; SE: Shannon entropy; T2D: Group of individuals with type 2 diabetes; VO2peak: Maximum volume of oxygen consumption
}

\section{Competing interests}

The authors declare that they have no competing interests.

\section{Authors' contributions}

SCGMT: Participated in the conception and design of the study, acquisition and analysis of data, interpretation of data, performed the statistical analysis and drafted the manuscript. ACMT: Participated in the analysis and interpretation of data helped to draft the manuscript. COF: Participated in the conception and design of the study, collection, acquisition of data and helped to draft the manuscript. SLBL: Participated in cardiology exam, clinical ergometric test and acquisition of data and revising it critically for important intellectual content. AMDV: Participated in collection and acquisition of data and revising it critically of manuscript. ABS: Participated in acquisition of data and revising it critically of manuscript. AMOL: Participated in the conception and design of the study and revising it critically of manuscript. NM: Participated in the analysis and interpretation of data and revising it critically for important intellectual content. AP: Participated in the analysis and interpretation of data and revising it critically for important intellectual content. AMC: Participated in the conception, design and coordination of the study and revising it critically for important intellectual content. All authors read and approved the final manuscript.

\section{Authors' information}

Sílvia Cristina Garcia de Moura Tonello is master in physiotherapy from Federal University of São Carlos, research interests and experiences on Diabetes Mellitus, cardiorespiratory fitness, pulmonary function and heart rate variability.

Anielle Cristhine de Medeiros Takahashi is professor in the Department of Physiotherapy in Federal University of São Carlos, São Paulo, Brazil. Her research interests are aging, frailty, complexity of biological signals. Cristina O. Francisco is master in physiotherapy from Federal University of São Carlos, research interests and experiences on Diabetes Mellitus, cardiorespiratory fitness, pulmonary function and inflammation. Sérgio Luiz Brasileiro Lopes is professor in the Department of Medicine, Federal University of São Carlos, specialized by the Brazilian Medical Association in Clinical Medicine, Cardiology and Intensive Care. Adriano M. Del Vale is physician specialized in pathology. Collaborator of Cardiovascular Physiotherapy Laboratory, Nucleus of Research in Physical Exercise at Physiotherapy Department at Federal University of São Carlos, São Paulo, Brazil.

Audrey Borghi e Silva is professor in the Department of Physiotherapy in Federal University of São Carlos, São Paulo, Brazil. She has experience in the area of physical therapy, with emphasis on Cardiorespiratory Physiotherapy and Exercise Physiology. Her research interests are non-invasive ventilation, ergogenic supplementation and study of pathophysiological mechanisms of exercise intolerance in cardiorespiratory disorders chronic

Ângela Merice de Oliveira Leal is professor in the Department of Medicine in Federal University of São Carlos. She has experience in the area of Medicine, with emphasis in Clinical Medicine, Endocrinology and Metabolism. Her research interests are endocrinology, diabetes and metabolism, molecular biology and system activin-myostatin.

Nicola Montano is professor in Department of Clinical Sciences, Internal Medicine II, L. Sacco Hospital, University of Milan, Milan, Italy. His research interests are neural control of cardiovascular function and the relationship between neural and cardiovascular oscillatory patterns.

Alberto Porta is professor in Department of Technologies for Health, Galeazzi Orthopaedic Institute, University of Milan, Milan, Italy. His research interests are time series analysis, nonlinear dynamics, system identification, and modeling applied to cardiovascular control mechanisms.

Aparecida Maria Catai is professor in the Department of Physiotherapy in Federal University of São Carlos, São Paulo, Brazil. She has experience in the area of physical therapy with emphasis in cardiovascular physical therapy and exercise physiology, responses of heart rate, blood pressure, heart rate variability, blood pressure variability, anaerobic threshold and ventilatory limitation to exercise, aerobic and resistive exercise and aging, cardiovascular diseases, respiratory and metabolic.

\section{Acknowledgements}

The authors thank the cardiologist Isabela Arruda Verzola Aniceto for her support during the clinical evaluation, and the volunteers for their cooperation throughout the study.

\section{Author details}

'Physiotherapy Department, Cardiovascular Physiotherapy Laboratory, Nucleus of Research in Physical Exercise, Federal University of São Carlos, São Paulo, Brazil. 'Department of Medicine, Federal University of São Carlos, São Paulo, Brazil. ${ }^{3}$ Department of Clinical Sciences, Internal Medicine II, L. Sacco Hospital, 
University of Milan, Milan, Italy. ${ }^{4}$ Department of Technologies for Health, Galeazzi Orthopaedic Institute, University of Milan, Milan, Italy.

Received: 2 October 2013 Accepted: 21 January 2014 Published: 1 February 2014

\section{References}

1. Whiting D, Unwin N, Roglic G: Diabetes: equity and social determinants. In Equity, social determinants and public health programmes. Chapter 5. Edited by Blas E, SivsankaraKurup A. Geneva: World Health Organization; 2010:77-94.

2. Goff DC Jr, Gerstein HC, Ginsberg HN, Cushman WC, Margolis KL, Byington RP, Buse JB, Genuth S, Probstfield JL, Simons-Morton DG: Prevention of cardiovascular disease in persons with type 2 diabetes mellitus: current knowledge and rationale for the action to control cardiovascular risk in diabetes (ACCORD) trial. Am J Cardiol 2007, 99:4i-20i.

3. Buse JB, Ginsberg HN, Bakris GL, Clark NG, Costa F, Eckel R, Fonseca V, Gerstein HC, Grundy S, Nesto RW, Pignone MP, Plutzky J, Porte D, Redberg R, Stitzel KF, Stone NJ: Primary prevention of cardiovascular diseases in people with diabetes mellitus: a scientific statement from the American heart association and the American diabetes association. Circulation 2007, 115:114-126.

4. Rolim LC, Sa JR, Chacra AR, Dib SA: Diabetic cardiovascular autonomic neuropathy: risk factors, clinical impact and early diagnosis. Arq Bras Cardiol 2008, 90:e24-e31.

5. Vinik Al, Maser RE, Mitchell BD, Freeman R: Diabetic autonomic neuropathy. Diabetes Care 2003, 26:1553-1579.

6. Montano N, Porta A, Cogliati C, Costantino G, Tobaldini E, Casali KR, lellamo F: Heart rate variability explored in the frequency domain: a tool to investigate the link between heart and behavior. NeurosciBiobehav Rev 2009, 33:71-80.

7. Sztajzel J: Heart rate variability: a noninvasive electrocardiographic method to measure the autonomic nervous system. Swiss Med Wkly 2004, 134:514-522.

8. Felber Dietrich D, Ackermann-Liebrich U, Schindler C, Barthelemy JC, Brandli O, Gold DR, Knöpfli B, Probst-Hensch NM, Roche F, Tschopp JM, Von Eckardstein A, Gaspoz JM: Effect of physical activity on heart rate variability in normal weight, overweight and obese subjects: results from the SAPALDIA study. Eur J ApplPhysiol 2008, 104:557-565.

9. Javorka M, Trunkvalterova Z, Tonhajzerova I, Javorkova J, Javorka K, Baumert M: Short-term heart rate complexity is reduced in patients with type 1 diabetes mellitus. ClinNeurophysio/ 2008, 119:1071-1081.

10. Takahashi AC, Porta A, Melo RC, Quiterio RJ, da Silva E, Borghi-Silva A, Tobaldini E, Montano N, Catai AM: Aging reduces complexity of heart rate variability assessed by conditional entropy and symbolic analysis. Intern Emerg Med 2012, 7:229-235.

11. Hautala AJ, Karjalainen J, Kiviniemi AM, Kinnunen H, Makikallio TH, Huikuri HV, Tulppo MP: Physical activity and heart rate variability measured simultaneously during waking hours. Am J Physiol Heart Circ Physiol 2010, 298:H874-H880.

12. Tulppo MP, Hughson RL, Makikallio TH, Airaksinen KE, Seppanen T, Huikuri HV: Effects of exercise and passive head-up tilt on fractal and complexity properties of heart rate dynamics. Am J Physiol Heart CircPhysiol 2001, 280:H1081-H1087.

13. Martinelli FS, Chacon-Mikahil MP, Martins LEB, Lima-Filho EC, Golfetti R, Paschoal MA, Gallo-Junior L: Heart rate variability in athletes and nonathletes at rest and during head-up tilt. Braz J Med Biol Res 2005, 38:639-647.

14. Porta A, Tobaldini E, Guzzetti S, Furlan R, Montano N, Gnecchi-Ruscone T: Assessment of cardiac autonomic modulation during graded head-up tilt by symbolic analysis of heart rate variability. Am J Physiol Heart CircPhysiol 2007, 293:H702-H708.

15. Zuttin RS, Moreno MA, César MC, Martins LEB, Catai AM, Silva E: Evaluation of autonomic heart rate modulation among sedentary young men, in seated and supine postures. Rev Bras Fisioter 2008, 12:7-12.

16. Perseguini NM, Takahashi AC, Rebelatto JR, Silva E, Borghi-Silva A, Porta A, Montano N, Catai AM: Spectral and symbolic analysis of the effect of gender and postural change on cardiac autonomic modulation in healthy elderly subjects. Braz J Med Biol Res 2011, 44:29-37.

17. Furlan R, Porta A, Costa F, Tank J, Baker L, Schiavi R, Robertson D, Malliani A, Mosqueda-Garcia R: Oscillatory patterns in sympathetic neural discharge and cardiovascular variables during orthostatic stimulus. Circulation 2000, 101:886-892.

18. Matsushima $\mathrm{R}$, Tanaka $\mathrm{H}$, Tamai $\mathrm{H}$ : Comparasion of the active standing test and head-up tilt test for diagnosis of syncope in childhood and adolescence. Clin Auton Res 2004, 14:376-384.

19. Expert Committee on the Diagnosis and Classification of Diabetes Mellitus: Report of the expert committee on the diagnosis and classification of diabetes mellitus. Diabetes Care 2003, 26(Suppl 1):S5-S20.

20. American Heart Association. Committee on Exercise: Exercise testing and training of apparently healthy individuals: a handbook for physicians. Dallas: American Heart Association; 1972

21. O'Brien IA, O'Hare P, Corrall RJ: Heart rate variability in healthy subjects: effect of age and the derivation of normal ranges for tests of autonomic function. Br Heart J 1986, 55:348-354.

22. Mezzani A, Agostoni $P$, Cohen-Solal A, Corrà U, Jegier A, Kouidi E, Mazic S, Meurin P, Piepoli M, Simon A, Laethem CV, Vanhees L: Standards for the use of cardiopulmonary exercise testing for the functional evaluation of cardiac patients: a report from the exercise physiology section of the European association for cardiovascular prevention and rehabilitation. Eur J CardiovascPrevRehabil 2009, 16:249-267.

23. Wasserman K, Hansen JE, Sue DY, Stringer WW, Whipp BJ: Principles of exercise testing and interpretation. Philadelphia: Lippincott Williams \& Wilkins; 1999.

24. Vanderlei LC, Silva RA, Pastre CM, Azevedo FM, Godoy MF: Comparison of the polar S810i monitor and the ECG for the analysis of heart rate variability in the time and frequency domains. Braz J Med Biol Res 2008, 41:854-859.

25. Porta A, Guzzetti S, Montano N, Furlan R, Pagani M, Malliani A, Cerutti S: Entropy, entropy rate, and pattern classification as tools to typify complexity in short heart period variability series. IEEE Trans Biomed Eng 2001, 48:1282-1291.

26. Porta A, Faes L, Mase M, D’Addio G, Pinna GD, Maestri R, Montano N, Furlan R, Guzzetti S, Nollo G, Malliani A: An integrated approach based on uniform quantization for the evaluation of complexity of short-term heart period variability: application to $24 \mathrm{~h}$ holter recordings in healthy and heart failure humans. Chaos 2007, 17:015117.

27. International Expert Committee: International expert committee report on the role of the A1C assay in the diagnosis of diabetes. Diabetes Care 2009, 32:1327-1334.

28. Munro BH: Statistical methods for health care research. 3rd edition. Philadelphia: JB Lippincott; 1997.

29. Ewing DJ, Campbell IW, Clarke BF: Heart rate changes in diabetes mellitus. Lancet 1981, 1:183-186.

30. Javorka M, Javorkova J, Tonhajzerova I, Calkovska A, Javorka K: Heart rate variability in young patients with diabetes mellitus and healthy subjects explored by Poincare' and sequence plots. ClinPhysiolFunct Imaging 2005, 25:119-127.

31. Khandoker $\mathrm{AH}$, Jelinek HF, Palaniswami M: Identifying diabetic patients with cardiac autonomic neuropathy by heart rate complexity analysis. Biomed Eng Online 2009, 8:3.

32. Guzzetti S, Borroni E, Garbelli PE, Ceriani E, Della Bella P, Montano N, Cogliati C, Somers VK, Malliani A, Porta A: Symbolic dynamics of heart rate variability: a probe to investigate cardiac autonomic modulation. Circulation 2005, 112:465-470.

33. Lindqvist A: Noninvasive methods to study autonomic nervous control of circulation. ActaPhysio/ScandSupp/ 1990, 588:1-107.

34. Porta A, Guzzetti S, Montano N, Pagani M, Somers V, Malliani A, Baselli G, Cerutti S: Information domain analysis of cardiovascular variability signals: evaluation of regularity, synchronisation and co-ordination. Med BiolEngComput 2000, 38:180-188

35. Ziegler D: Diabetic cardiovascular autonomic neuropathy: prognosis, diagnosis and treatment. Diabetes MetabRev 1994, 10:339-383.

36. Dias RJS, Carneiro AP: Neuropatia diabética: fisiopatologia, clínica e eletroneuromiografia. Acta Fisiátrica 2000, 7:35-44

37. Pop-Busui R: Cardiac autonomic neuropathy in diabetes: a clinical perspective. Diabetes Care 2010, 33:434-441.

38. Valensi P, Parie's J, Attali JR, French Group for Research and Study of Diabetic Neuropathy: Cardiac autonomic neuropathy in diabetic patients: influence of diabetes duration, obesity, and microangiopathic complications - the French multicenter study. Metabolism 2003, 52:815-820.

39. Mäkimattila S, Schlenzka A, Mäntysaari M, Bergholm R, Summanen P, Saar $P$, Erkkilä H, Yki-Järvinen $\mathrm{H}$ : Predictors of abnormal cardiovascular autonomic 
function measured by frequence domain analysis of heart rate variability and conventional tests in patients with type 1 diabetes. Diabetes Care 2000, 23:1686-1693.

40. Chen SR, Lee YJ, Chiu HW, Jeng C: Impact of glycemic control, disease duration and exercise on heart rate variability in children with type 1 diabetes mellitus. J Formos Med Assoc 2007, 106:935-942.

41. Nolan RP, Barry-Bianchi SM, Mechetiuc AE, Chen MH: Sex-based differences in the association between duration of type 2 diabetes and heart rate variability. DiabVasc Dis Res 2009, 6:276-282.

42. Valensi $P$, Extramiana $F$, Lange $C$, Cailleau M, Haggui A, Maison Blanche $P$, Tichet J, Balkau B: Influence of blood glucose on heart rate and cardiac autonomic function. The DESIR study. Diabetic Med 2011, 28(4):440-449.

43. Van De Borne P, Hausberg M, Hoffman RP, Mark AL, Anderson EA: Hyperinsulinemia produces cardiac vagal withdrawal and nonuniform sympathetic activation in normal subjects. Am J Physiol 1999, 276:178-183.

doi:10.1186/1758-5996-6-13

Cite this article as: Moura-Tonello et al:: Influence of type 2 diabetes on symbolic analysis and complexity of heart rate variability in men.

Diabetology \& Metabolic Syndrome 2014 6:13.

\section{Submit your next manuscript to BioMed Central and take full advantage of:}

- Convenient online submission

- Thorough peer review

- No space constraints or color figure charges

- Immediate publication on acceptance

- Inclusion in PubMed, CAS, Scopus and Google Scholar

- Research which is freely available for redistribution 